\title{
FDA debates trial-data secrecy
}

\section{US drug regulator weighs up merits of disclosing preliminary results.}

\section{BY HEIDI LEDFORD}

$\mathrm{D}$ espite a trend towards increased transparency in clinical-trial data, the US Food and Drug Administration (FDA) is asking whether there are times when participants and researchers should be kept in the dark. As pharmaceutical companies push for studies that first justify a drug's approval, then monitor safety once it reaches the market, the agency fears that publicizing the early data could bias the final results.

In raising the matter, the FDA could energize the debate about a long-standing clinical conundrum, says Iain Chalmers, coordinator of the James Lind Initiative, a group based in Oxford, UK, that aims to improve clinical trials. "There hasn't been much discussion about this," he says. "There needs to be much more."

On 11 August, the FDA will hold a public hearing in Silver Spring, Maryland, to discuss situations in which preliminary results from clinical trials should be kept confidential. The FDA is obliged to release a summary of the data that it uses to approve a drug. But the public rarely sees the data given to safety committees to decide whether a trial should continue. Even if those data are not definitive but lean one way or another, making them public may spook study participants or bias investigators towards a particular outcome, the agency fears.

\section{SCIENCE OVER SUBJECTS}

The practice of confidentiality has been debated by researchers and ethicists for some time, and FDA memos arguing in favour of withholding some interim data have not convinced everyone. Although the memos have pointed out many possible negative consequences for a trial if such data are divulged, they have ignored the ethical ramifications of keeping information from participants, says Michael Carome, director of the healthresearch group at Public Citizen, a non-profit consumer advocacy group in Washington DC. "The agency wants to get an answer to scientific questions," he says. "The question is: in order to get their wish, are they perhaps putting human subjects at risk?"

Changes to the drug-approval process have made that question trickier than ever. In the past, sponsors rarely submitted interim data to the FDA. But in 2007, researchers found signs that a popular diabetes drug may have been increasing deaths due to cardiovascular events such as heart attacks or strokes. As a result, the agency began to demand large, prolonged safety trials of some diabetes drugs (see

\section{MUM'S THE WORD}

When approving the diabetes medication alogliptin, the US Food and Drug Administration deviated from its usual practice of publicly releasing the supporting data.

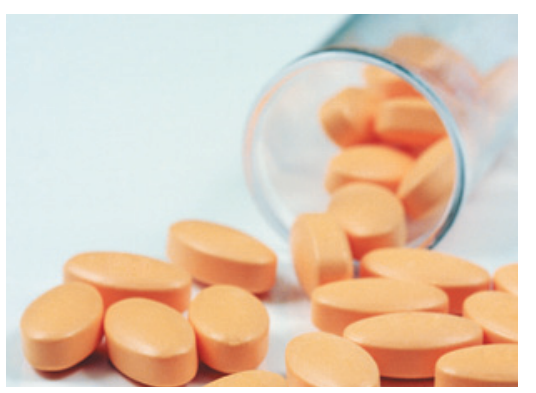

4 JANUARY 2008 The Japanese firm Takeda Pharmaceuticals applies to the FDA for approval of its diabetes drug alogliptin.

\section{DECEMBER 2008 The FDA issues} detailed standards for cardiovascularsafety tests of new diabetes drugs.

\section{AUGUST 2009 Researchers} launch clinical trial to test cardiovascular safety of alogliptin.

\section{JULY 2011 The FDA receives} interim data from safety trial.

\section{JANUARY 2013 The FDA} approves alogliptin but does not release interim data.

\section{OCTOBER 2013 Final results of} safety trial are published and show no evidence of cardiovascular risk.

\section{AUGUST 2014 The FDA is holding} a public meeting to discuss disclosure of interim clinical-trial data.

'Mum's the word'). Pharmaceutical companies are typically allowed to market those drugs once they have showed that it raises the risk of cardiovascular events by no more than $80 \%$ relative to the control group; then they are asked to do a post-approval study demonstrating that the drug boosts that risk by no more than $30 \%$.

Increasingly, companies are petitioning to combine the two studies into one large trial, and use interim data to clear the first hurdle.
One such case came to the FDA in 2011, when it evaluated alogliptin, a diabetes drug made by Takeda Pharmaceuticals in Osaka, Japan. Interim analyses of the drug's heart risks were conducted once 81 cardiovascular events had been seen in study participants, says William White, a specialist in preventive cardiology at the University of Connecticut School of Medicine in Farmington, who led the study. Those data showed that the drug did not greatly affect the rate of cardiovascular events, White says, but could have been misinterpreted to suggest that the drug actually lowered the risk.

\section{EARLY RELEASE}

Rather than releasing those data when it approved alogliptin in January 2013, the FDA simply announced that the findings showed that the trial was safe enough to proceed. In a March 2013 memo, Mary Parks, head of endocrinology products at the FDA's Center for Drug Evaluation and Research in Silver Spring, argued that the secrecy was necessary so that long-term safety data could be obtained in a timely fashion.

White, who says that even he did not see the data until the study was finished, says that secrecy was key to successful completion of the trial because investigators might have refused to put patients on placebo had they seen the interim data.

The final results, published in October, confirmed that the drug had no significant effect on cardiovascular risk (W. White et al. N. Engl. J. Med. 369, 1327-1335; 2013).

The release of interim results might also prompt patients to abandon a trial, but that should be their choice, says Richard Lilford, chair of public health at the University of Warwick, UK. He argues that trial designers too often default to secrecy, and risk sacrificing their obligation to participants in the process. Instead, he advocates that the data be shared from the start. "Among the trial fraternity, this idea is terribly unpopular," he says. "They think that clinical trials must run until they've got a clear answer."

Paul Armstrong, a cardiologist at the University of Alberta in Canada, has served on more than 30 safety boards and says that it is standard to keep interim data confidential. But sometimes, he says, boards do decide that the benefits of revealing the data outweigh the risks. "We always ask ourselves, 'could we go and get consent for the next patient and feel confident they were adequately informed about participating in the trial?' That is the bottom line." - 